\title{
Liberdade de expressão: como lutar por ela
}

\author{
Maria Cristina Castilho Costa \\ Doutora em Ciências Sociais pela FFLCH-USP, livre-docente em Ciências da Comunicação pela \\ ECA-USP, professora associada 3 da ECA-USP, coordenadora do Observatório de Comunicação, \\ Liberdade de Expressão e Censura da USP e autora do livro A Censura em Cena, publicado \\ pela EDUSP e Imprensa Oficial. \\ E-mail: criscast@usp.br
}

Resumo: $O$ presente artigo mostra como a censura tem feito parte da vida política brasileira desde os tempos coloniais e como se mantém ativa na atualidade, mesmo estando o direito à liberdade de expressão garantido pela Constituição de 1988. O texto relata pesquisas do Observatório de Comunicação, Liberdade de Expressão e Censura da USP, OBCOM-USP, segundo as quais apenas aqueles que fazem uso da fala e da expressão dão valor a esse direito, e alerta os educadores para a importância da sua prática para a defesa da nossa cultura e cidadania.

Palavras-chave: liberdade de expressão; censura; cidadania; OBCOM-USP.
Abstract: This paper discusses how censorship has been part of Brazilian political life since Colonial times and how it remains active today, even though the right to freedom of expression is guaranteed by the 1988's Brazilian Constitution. This paper describes researches from the Observatory on Communication, Freedom of Expression and Censorship at USP, according to which only those who make use of speech and expression give value to this right, and it also alerts educators to the importance of their practices for the defense of our culture and citizenship.

Keywords: freedom of expression; censorship; citizenship; OBCOM-USP.

No Brasil, a censura chegou antes da imprensa, do teatro e das bibliotecas. Durante a colonização, a coroa portuguesa proibia que em terras brasileiras fossem publicados livros e jornais, que se fizessem apresentações públicas sem apoio, incentivo e consentimento das ordens religiosas (guardiãs da fé cristã e da hegemonia metropolitana), bem como eram controlados os acervos de livros, até mesmo os particulares. Um dos incidentes mais conhecidos da prática dessa censura chegou até nós através do livro $O$ diabo na livraria do cônego ${ }^{1}$, de Euardo Frieiro. Nele, o autor, com base nos Autos da Devassa, documentos do processo de condenação dos participantes da Inconfidência Mineira, relata que o cônego Luis Vieira da Silva fora condenado pela Inquisição, entre outros motivos, por possuir, ler e emprestar uma lista de livros condenáveis. Frieiro mostra que, como quase todas as bibliotecas da época, a de Vieira também apresentava uma miscelânea de títulos e gêneros - tratados de biologia, dicionários, livros de retórica e filosofia iluminista. Mas, seja por tratar da investigação científica de cunho positivista, seja por difundir ideais anticlericais, esses livros eram considerados incendiários, isto é, capazes de despertar curiosidade e descrença.

Recebido em: 15/03/2013 Aprovado em: 22/05/2013

1. FRIEIRO, Eduardo. O diabo na livraria do cônego. São Paulo: EDUSP; Belo Horizonte: Itatiaia, 1957. 
Para evitar os prejuízos à ordem colonial que eles pareciam ameaçar, os títulos pertencentes às raras bibliotecas da colônia passavam por diversos processos censórios. Voltaire, por exemplo, só chegava a ser lido no Brasil depois de vencer as barreiras censórias que havia entre Portugal e o resto da Europa, a censura que fiscalizava os livros que embarcavam para as colônias e, finalmente, a censura que sofriam ao desembarcarem em terras brasileiras.

Mas a censura aos livros não era privilégio da colonização portuguesa. Ricardo Palma, em Anais da Inquisição de Lima ${ }^{2}$, investiga também os Autos da Inquisição promovida pela Igreja Católica em terras de colonização americana. Através desses documentos, é possível saber que muitos condenados o foram por possuir livros proibidos, por lê-los ou emprestá-los.

Entretanto, não foram apenas a imprensa e a publicação de livros proibidas nos tempos coloniais. Controlaram-se crenças, opiniões, linguagens, assim como proibiram-se idiomas nativos, deuses "estrangeiros", instrumentos musicais inconvenientes e danças consideradas indecentes. Em A língua escravizada ${ }^{3}$, Florence Carboni e Mário Maestri defendem que o Brasil foi um caldeirão de línguas, idiomas e dialetos de origem indígena e africana, os quais, misturando-se ao português, criaram o que ficou conhecido por língua geral, sistematizada, mais tarde, pelos jesuítas. É de 1595 a Arte da gramática da língua mais usada na costa do Brasil, de José de Anchieta. Essa era a língua que permitia não só a evangelização e o comércio, como o sucesso de qualquer empreendimento que dependesse da comunicação e do estabelecimento de relações na colônia. Ao lado dela, entretanto, sobrevivia o kibundo, na Bahia, sistematizado na gramática do jesuíta Pedro Dias, em 1695. Na Amazônia, falava-se o tupi-guarani, nas regiões de Minas Gerais, escutava-se o mina, na Bahia, o nagô, também chamado de língua da costa. Pois foi no século XVIII, após a expulsão dos jesuítas, que a Coroa Portuguesa decretou a união linguística e a obrigatoriedade do português. "Quarenta anos mais tarde, no Espírito Santo, o Senado da Câmara ordenava que só se falasse a língua portuguesa, sob pena de prisão." Até hoje, pouco mais de duzentos anos depois, as dificuldades e resistências em relação ao português podem ser, em parte, explicadas por essa diversidade, complexidade e proliferação de línguas que acabaram sendo proibidas. Muitos historiadores reiteram que havia proibição de rituais religiosos considerados capazes de trazer malefícios para os brancos e senhores de escravos. Tais bruxarias foram perseguidas pelas visitações, como nos conta Laura de Mello e Souza no livro O diabo e a Terra de Santa Cruz ${ }^{5}$.

\section{SINCRETISMOS E RESISTÊNCIAS}

Numa colônia de diversificada população indígena e africana, com uma economia exploratória e escravista, o controle da expressão e da informação foi logo implantado pela Coroa Portuguesa, cabendo à Administração e à Igreja a sua fiscalização. E onde há controle e censura, há resistência. Com igual rapidez, colonos e escravos aprenderam a resistir, a dissimular e a encobrir, 
promovendo-se uma cultura da camuflagem, do sincretismo, do disfarce, da ironia e do humor. Bigamias, mestiçagens, bastardia mostram que, para além do que rezavam as regras coloniais e religiosas, a população da colônia encontrava formas de infringi-las. Judeus recém-convertidos disfarçavam-se de cristãos; sacerdotes mantinham mulheres amancebadas que se apresentavam como sobrinhas, mestiços bastardos eram criados juntos aos filhos legítimos das famílias brancas e santos do pau oco permitiam o transporte de minérios através da fiscalização colonial. Ambiguidades como essas também eram praticadas por sacerdotes que, não confiando apenas no poder das orações, mandavam os fiéis recorrerem aos negros benzedeiros para curar doenças ou garantir uma boa viagem. Luiz Mott conta que o carmelita Frei Bernardo de Vasconcelos, justificando-se diante do Santo Ofício do Rio de Janeiro por informações omitidas sobre uma embusteira santa Rosa Egipcíaca, afirma: “... o crivo do Brasil é muito largo, e passa não só a farinha e o farelo, mas ainda o grão inteiro passa” ${ }^{\text {. }}$

Se essas estratégias, por um lado, enriqueceram nossa cultura, também nos deram uma perigosa tolerância em relação às interdições e aos autoritarismos - passamos a conviver com eles como se fossem parte da natureza das relações sociais e das razões de Estado. Desde tempos remotos, temos suspeitas acerca de nossa fé, de nossa opinião e da conveniência de nossos dizeres. Desde tempos remotos, tivemos as visitações do Santo Ofício buscando identificar heréticos, blasfemos, malfalados e malfalantes.

E, se por um lado, o disfarce, o sincretismo e a simulação permitiram a sobrevivência e a resistência ao poder, por outro, engendraram uma relação dúbia com a autoridade, baseada na negociação, na cumplicidade e na tolerância. Com base nessa ideia, Marilena Chauí identifica na história do país a instituição de um poder de cunho mítico/messiânico, a partir do qual a autoridade é vista como sagrada e os súditos como fiéis. Representando Deus e não o povo, o poder se baseia em uma concepção messiânica e teocêntrica que dá origem aos caudilhismos, coronelismos e populismos ${ }^{7}$.

Diz a autora: "Não existe, no Brasil, a ideia, vinda da Revolução Francesa, de igualdade de direitos e de igualdade jurídica dos cidadãos. A forma autoritária da relação é mascarada por aquilo mesmo que a realiza e a conserva: as relações de favor, tutela e clientela" .

\section{INDEPENDENTES, MAS NEM TANTO}

Essa postura teocêntrica em relação ao poder e essa atitude de negociação e disfarce dos cidadãos em relação a ele se tornam mais explícita após a Independência, na medida em que se manteve a estrutura social básica da época colonial: escravidão, latifúndio, monarquia e dependência externa. Com relação à produção simbólica, mantivemos também a mesma postura sincrética e tolerante. E a Monarquia, por sua vez, encampou todas as formas usuais de censura e ainda criou outras, agora atreladas ao aparelho do Estado que se pretendia constituir.
6. MOTT, Luiz. Cotidiano e vivência religiosa: entre a capela e o calundu. In: MELLO E SOUZA, Laura de (Org.). História da vida privada no Brasil: cotidiano e vida privada na América Portuguesa. São Paulo: Cia. das Letras, 1997. p. 199.

7. CHAUÍ, Marilena de Souza. Raízes teológicas do populismo no Brasil: teocracia dos dominantes, messianismo dos dominados. In: DAGNINO, Evelina (Org.). Anos 90: política sociedade no Brasil. São Paulo: Brasiliense, 1994.

8. Idem, p. 27. 
Passamos a ter, com a Independência e a Monarquia, órgãos especialmente destinados ao fomento das artes laicas e ao controle do que se fazia com elas. Desde 1841, nenhuma apresentação pública se faria sem aprovação e visto do Chefe de Polícia, guardião da moral, da religião e da decência pública. De 1834 a 1843, época da Regência, nenhuma apresentação teatral foi permitida, temendo-se que o teatro se tornasse palco (literalmente) de agitações republicanas e abolicionistas. Em 1843, foi criado o Conservatório Dramático Musical onde colaboraram como censores nomes importantes das artes e da intelectualidade - João Caetano, Quintino Bocaiuva e Machado de Assis, que, com esse trabalho, recebiam algum rendimento e privavam intimidade com o poder. Machado exerceu as funções de censor de 1862 a 1864, período em que, dentre os dezesseis pareceres que elaborou, pediu para Augusto César de Lacerda modificar o desenlace da peça Mistérios Sociais, na qual uma baronesa abandona o marido por um escravo. Para que os autores recebessem com humildade os ditames do Conservatório Dramático, Machado recomendava: "Tenham presente a ideia de que o teatro é uma escola de costumes e que há na sala ouvidos castos e modestos que o ouvem".

"Não devem aparecer em cena assuntos nem expressões menos conformes com o decoro, os costumes e as atenções que em todas as ocasiões se devem guardar, maiormente naquelas em que a Imperial Família honrar com a sua presença o espetáculo", informava a regulamentação estabelecida pelo Conservatório $^{10}$.

Livros e jornais (já havia imprensa no Brasil e ela proliferava) também estavam sujeitos à censura, se fossem defensores da República, do fim da escravidão, ou favoráveis à união entre as coroas portuguesa e brasileira. Assim, já se estabelecia uma distinção nas práticas censórias - as chamadas diversões públicas, como o teatro, o circo e os espetáculos públicos, estavam sujeitas à censura prévia, determinada por lei. Já a imprensa só sofreu censura prévia em períodos ditatoriais, mas, sabe-se, jornais e revistas que davam voz a partidos de oposição ou às reivindicações de movimentos populares eram alvo de intensa perseguição, que ia da prisão dos responsáveis à destruição de oficinas gráficas.

Num país independente, mas com estruturas políticas e econômicas arcaicas e no qual as instituições artísticas, educacionais e culturais começavam a impulsionar a produção simbólica, a dependência dos artistas e escritores ao Estado mantinha-os submissos aos interesses políticos hegemônicos. Aos mais arrojados, que fugiam a essa cumplicidade ideológica, havia a força das leis e da polícia.

9. Parecer presente na documentação examinada na Biblioteca Nacional, em 2005.

10. SOUSA, J. Galante de. O teatro no Brasil. Rio de Janeiro: Tecnoprint, 1968. p. 371.

\section{REPÚBLICA, ESTADO NOVO E GUERRA FRIA}

Quando se eliminou o trabalho escravo no Brasil, a Monarquia ruiu e, com ela, muito do que restava de uma estrutura colonial agonizante agrária e latifundiária. No século XX, ocorrem mudanças profundas promovidas pela 
riqueza resultante da cafeicultura, da indústria nascente e da urbanização. Os meios de comunicação se desenvolvem - cinema, rádio e indústria fonográfica, além da imprensa escrita. Começa-se a produzir um jornalismo e uma arte mais regular, fecunda e nacionalista, mas sempre atrelada aos ditames do Estado, misturando a sede de autonomia com o paternalismo, o clientelismo e a censura. A vida social se agita com as partidas de futebol, as corridas, os teatros de revista e as quermesses. O controle de toda essa produção cultural, que, na Monarquia, estava intimamente relacionada à figura do Imperador, na República, assume um caráter mais impessoal e burocrático. A legislação previa a fiscalização policial aos espetáculos em nome da proteção à população e à ordem pública. Uma extensa legislação regulamentava toda sorte de fiscalização à produção simbólica.

Quando, na década de 1930, Getúlio Vargas, inspirado por chefes de governos nazifascistas, como Mussolini e Salazar, instaura o Estado Novo, instituiu formas de censura à imprensa e aos meios de comunicação que fariam inveja aos inquisidores medievais. Pretendendo subvencionar e incentivar as artes e as comunicações, assim como usá-las na propaganda política, Vargas criou o Departamento de Imprensa e Propaganda (DIP), responsável também pela prisão de jornalistas e a perseguição a jornais da oposição. E, apesar dos ares libertários promovidos pela Semana de Arte Moderna, vivemos um período conturbado, cujas disputas foram se tornando cada vez mais agudas. Dessa época foram diretores do Departamento Estadual de Imprensa e Propaganda do Estado de São Paulo (DEIP - filial estadual do DIP) poetas como Menotti Del Picchia e Cassiano Ricardo, que também atuaram como censores. Até Vinícius de Moraes serviu como censor ao cinema, antes mesmo de ser diplomata, evidenciando uma convivência escandalosa entre artistas, intelectuais e o poder.

À medida que o recurso à censura se tornava cada vez mais cotidiano, o governo Vargas se defendia. Celso Vieira, diretor do serviço de censura do Distrito Federal, argumenta:

A censura não é um meio violento restritivo da liberdade. É, exclusivamente, um remédio profilático, preventivo, de que lança mão a autoridade pública, no legítimo exercício de sua defesa própria... sua prática constitui dever precípuo e máximo das autoridades constituídas ${ }^{11}$.

Após a Segunda Guerra Mundial, caem as ditaduras de cunho fascista e, entre elas, o Estado Novo de Getúlio, mas sobrevivem as instituições políticas autoritárias. Com a oposição que se estabelece entre a União Soviética e os Estados Unidos, o recurso ao controle da comunicação e da informação desencadeou uma verdadeira Guerra Fria Cultural ${ }^{12}$, com os governos comunistas perseguindo jornalistas e artistas dissidentes, e os governos capitalistas atacando toda e qualquer produção considerada subversiva. Alinhando-se nesse segundo grupo, o Brasil, até mesmo depois do Estado Novo e durante governos considerados democráticos como o de Juscelino Kubitschek, utilizou a censura para conter o pensamento de oposição e a crítica política.
11. Diário de São Paulo, 11 de fevereiro de 1936. In: COSTA. Maria Cristina Castilho. Censura em cena. São Paulo: EDUSP/ Imprensa Oficial/FAPESP, 2006. p. 101.

12. SAUNDERS, Frances Stonor. The cultural cold war. New York: The New Press, 1999. 
Mas foi durante a Ditadura Militar, nos anos de chumbo (1964-1984), que a censura e a perseguição política à oposição e às manifestações consideradas subversivas transformam-se em repressão, deixando de lado qualquer justificativa, aparência ou intenção de defesa da sociedade ou de proteção às artes e à cultura. A partir da promulgação do Ato Institucional n. 5 - AI-5, os militares declararam guerra a todas as manifestações críticas e a toda arte de vanguarda minimamente nacionalista ou defensora da liberdade política ou da igualdade social. Autores, atores, diretores, produtores, jornalistas e demais profissionais da comunicação foram alvo de prisão, morte, perseguição, exílio e toda forma de violência. Completando quase cinco séculos de existência de controle, fiscalização e censura da produção simbólica por parte do poder estabelecido em diferentes épocas, o abuso do poder chega a colocar em risco a própria sobrevivência da arte e da cultura nacionais.

Foi preciso que se chegasse a esses extremos para que a sociedade reagisse e, com o fim da Ditadura Militar, fosse extinta a censura oficial e houvesse o reconhecimento do direito constitucional à liberdade de expressão no país.

\section{A CENSURA NA ATUALIDADE}

O Observatório da Comunicação, Liberdade de Expressão e Censura da USP, OBCOM-USP, reúne pesquisadores que estudam práticas de interdição à liberdade de expressão que ocorrem na atualidade, quando os principais órgãos estatais dedicados à censura foram praticamente extintos no Ocidente. Charges com a imagem do profeta Maomé, publicadas no Jyllands-Posten, na Dinamarca, provocaram grande comoção quando apresentadas na rede de televisão árabe Al-Jazeera, em 2006. Consideradas sacrílegas pelos árabes, resultaram em ameaças feitas aos jornais e redatores ocidentais que as divulgassem. Produções audiovisuais têm gerado controvérsia. A inocência dos Muçulmanos - vídeo anti-islâmico publicado na Internet - provocou grande manifestação por parte da mídia e muitos protestos por parte dos muçulmanos que o consideram antiárabe. O diretor iraniano Jafar Panahi, responsável por diversos filmes de caráter político-social, foi condenado a seis anos de prisão, sendo também proibido de filmar por vinte anos. Foi filmado por um colega, em sua residência, em contundente depoimento sobre sua situação. Esse material, compondo o filme Isto não é um filme, saiu do Irã em um pen drive e foi apresentado no Festival de Cannes, em 2011.

Outros conflitos envolvendo diferentes países têm ocorrido, tendo a liberdade de expressão e a censura como principal questionamento. A prisão e asilo político na Embaixada do Equador do responsável pelo site Wikileaks, em 2011, o australiano Julian Assange, acusado de assédio sexual a jovens suecas, expõe os recursos internacionais de censura que vigoram no aparentemente livre espaço da Internet. Ele é tido como o grande responsável pelo "vazamento" de documentos sigilosos do exército norte-americano publicados na rede mundial de computadores. 
No Brasil, diversos exemplos mostram que a censura subsiste de forma indireta, disfarçada por outros recursos como processos judiciais contra difamação, ausência de apoio financeiro para jornais, revistas ou produções artísticas inconvenientes, ou simplesmente o silêncio em torno deles. Nessa linha, estão a censura à biografia Roberto Carlos em Detalhes, de autoria de Paulo César de Araújo, publicada pela Editora Record, em 2002, e a proibição do jornal $O$ Estado de São Paulo de publicar qualquer notícia sobre supostas irregularidades praticadas pelo empresário Fernando Sarney, em 2009. A proibição do uso do nome Falha de São Paulo, pelos jornalistas Lino e Mário Bocchini em seu blog, sob acusação de uso indevido da marca, em 2013, é um dos casos mais recentes de interdição. De fato, proibia-se a crítica irônica feita pelos blogueiros a esse jornal da grande imprensa.

As pesquisas levadas a efeito pelo OBCOM-USP mostram que as interdições ao direito à liberdade de expressão são reclamadas principalmente por aqueles que fazem uso da palavra, que costumam ser ouvidos ou que, por hábito, expressam suas opiniões. Professores, jornalistas, artistas em geral, escritores, editores, produtores culturais são os que se mobilizam em defesa da liberdade de expressão. Essa constatação abre os olhos dos pesquisadores para a importância de se difundir e defender atividades nas quais se possa experimentar a gratificante oportunidade de ter espaço e voz na sociedade. É fazendo uso da palavra, dos meios de comunicação, da possibilidade de opinar e de ser ouvido que cidadãos passam a dar importância ao direito à livre expressão e, consequentemente, a lutar por ele. Temos certeza de que a única forma de convivermos em uma cultura plural e democrática está em habituar os cidadãos à sua prática, integrando-os nela. E, parece-nos, essa deve ser uma premissa de todo processo educativo consistente e responsável. Só assim poderemos fazer frente a uma tradição secular de interdição à produção simbólica que atravessou todos os períodos de nossa história. Só assim deixaremos o paternalismo, o disfarce, o clientelismo e a cumplicidade que procuraram, e conseguiram muitas vezes, interditar a crítica, a opinião e o livre expressar.

\section{REFERÊNCIAS BIBLIOGRÁFICAS}

CARBONI, Florence; MAESTRI, Mário. A linguagem escravizada: língua, história, poder e luta de classes. São Paulo: Expressão Popular, 2003.

CHAUÍ, Marilena de Souza. Raízes teológicas do populismo no Brasil: teocracia dos dominantes, messianismo dos dominados. In: DAGNINO, Evelina (Org.). Anos 90: política sociedade no Brasil. São Paulo: Brasiliense, 1994.

COSTA, Maria Cristina Castilho. Censura em cena. São Paulo: EDUSP/Imprensa Oficial/FAPESP, 2006.

Teatro e censura: Vargas e Salazar. São Paulo: EDUSP/FAPESP, 2010.

FRIEIRO, Eduardo. O diabo na livraria do cônego. São Paulo: EDUSP; Belo Horizonte: Itatiaia, 1957. 
MOTT, Luiz. Cotidiano e vivência religiosa: entre a capela e o calundu. In: MELLO E SOUZA, Laura de (Org.). História da vida privada no Brasil: cotidiano e vida privada na América Portuguesa. São Paulo: Cia. das Letras, 1997.

PALMA, Ricardo. Anais da Inquisição de Lima. São Paulo: EDUSP/Ed. Giordano, 1992.

SAUNDERS, Frances Stonor. The cultural cold war (A guerra fria cultural). New York: The New Press, 1999.

SOUSA, J. Galante de. O teatro no Brasil. Rio de Janeiro: Tecnoprint, 1968.

SOUZA, Laura de Mello. O Diabo e a Terra de Santa Cruz. São Paulo: Cia. das Letras, 1986. 